\title{
Auxiliary in vitro and in vivo biological evaluation of hydrogen peroxide sensitive prodrugs of methotrexate and aminopterin for the treatment of rheumatoid arthritis
}

Previtali, Viola; Petrovic, Katarina; Peiro Cadahía, Jorge; Troelsen, Nikolaj Sten; Clausen, Mads Hartvig

Published in:

Bioorganic \& Medicinal Chemistry

Link to article, DOI:

10.1016/j.bmc.2019.115247

Publication date:

2020

Document Version

Peer reviewed version

Link back to DTU Orbit

Citation (APA):

Previtali, V., Petrovic, K., Peiro Cadahía, J., Troelsen, N. S., \& Clausen, M. H. (2020). Auxiliary in vitro and in vivo biological evaluation of hydrogen peroxide sensitive prodrugs of methotrexate and aminopterin for the treatment of rheumatoid arthritis. Bioorganic \& Medicinal Chemistry, 28(2), [115247].

https://doi.org/10.1016/j.bmc.2019.115247

\section{General rights}

Copyright and moral rights for the publications made accessible in the public portal are retained by the authors and/or other copyright owners and it is a condition of accessing publications that users recognise and abide by the legal requirements associated with these rights.

- Users may download and print one copy of any publication from the public portal for the purpose of private study or research.

- You may not further distribute the material or use it for any profit-making activity or commercial gain

- You may freely distribute the URL identifying the publication in the public portal 


\title{
Auxiliary in vitro and in vivo biological evaluation of hydrogen peroxide sensitive prodrugs of methotrexate and aminopterin for the treatment of rheumatoid arthritis
}

\author{
Viola Previtali, Katarina Petrovic, Jorge Peiró Cadahía, Nikolaj Sten Troelsen, Mads H. Clausen* \\ Center for Nanomedicine \& Theranostics, Department of Chemistry, Technical University of Denmark, Kemitorvet 207, DK- \\ 2800 , Kongens Lyngby, Denmark
}

*Corresponding author: mhc@kemi.dtu.dk

\begin{abstract}
Rheumatoid arthritis (RA) is a chronic inflammatory disease that causes severe joints damage and other extra-articular alterations. Despite the efficacy of low-dose methotrexate (LD-MTX) in RA treatment, adverse effects are the predominant reasons for discontinuation of therapy. As a therapeutic targeting strategy, the presence of increased concentrations of reactive oxygen species (ROS) in the inflammatory environment can serve as the stimulus for prodrug activation in siteselective drug delivery systems. Our group has previously reported novel ROS sensitive prodrugs (13) of MTX and aminopterin (AMT) for site-selective delivery to inflammatory tissue associated with $R A$, with the aim of reducing side effects in RA therapy. Herein, we investigate the effect and toxicity of the same prodrugs in a rat CIA (collagen-induced arthritis) model of RA. We find that prodrug 1, an arylboronic acid ROS-sensitive MTX-prodrug, displays similar in vivo efficacy as MTX at an equimolar dose, while avoiding adverse effects known to restrict $\mathbf{M T X}$ treatment. To further characterize prodrug $\mathbf{1}$ and its ROS mediated activation, we synthesized compound $\mathbf{4}$, a negative control lacking the boronic acid moiety. We then investigated the effect of molecules on cell proliferation and cytotoxicity in the presence of the ROS scavenger pyruvate, as well as their stability in buffer and cell media, demonstrating a direct correlation between ROS concentration and the prodrug activity. Moreover, the in vitro ADME properties were investigated, including permeability, rat plasma and microsomal stability.
\end{abstract}

\section{Keywords}

Rheumatoid arthritis; Inflammation; Methotrexate; Aminopterin; Prodrug; Boronic Acids; Reactive oxygen species

\section{Introduction}

Rheumatoid arthritis (RA) is one of the most prevalent chronic inflammatory joint disease and is associated with joints damage and progressive disability. ${ }^{1}$ RA is considered a burden for both the individual and society and the factors causing disease remain unknown. ${ }^{2}$ Advances in understanding the pathogenesis of the disease have brought new treatment strategies, but several unmet needs persist. ${ }^{3}$ Aminopterin (AMT) was initially tested for RA treatment ${ }^{4}$ but its toxicity and low therapeutic index led to the development of methotrexate (MTX) as an alternative antifolate for cancer therapy, which later showed antiarthritic properties as a disease modifying antirheumatic drug (DMARD). ${ }^{5}$ Despite the advent of effective biologic DMARDs, MTX remains the anchor drug for the treatment of 
RA. ${ }^{6}$ Folate antagonism is an important mechanism of action for MTX, but other anti-inflammatory activities contribute to the complex pharmacology that makes low-dose methotrexate efficacious in the treatment of inflammatory disorders. ${ }^{7,8}$ One of the drawback of these complex and multifaceted mechanisms of action is the variety of side effects that are often associated with MTX therapy and responsible for the discontinuation of treatment in many cases (e.g. gastrointestinal side effects, hepatotoxicity, nephrotoxicity, pulmonary and hematologic toxicity). ${ }^{9}$

Reactive oxygen species (ROS, e.g. $\mathrm{H}_{2} \mathrm{O}_{2}$ ), have important physiological roles, and oxidative stress has also been described to be an important factor in the pathogenesis of inflammation in RA. ${ }^{10}$ In order to counter balance this oxidative dysfunction, large amounts of antioxidants like glutathione (GSH) are recruited in the inflammatory region, contributing to a change in the local microenvironment that has been suggested as a means to control release of therapeutic agents in RA treatment. ${ }^{11,12}$

Prodrugs are chemically modified molecules that possess little or no pharmacological activity and that are converted to the active parent drug in vivo by enzymatic or chemical reactions. ${ }^{13}$ The presence of increased concentrations of ROS (among which $\mathrm{H}_{2} \mathrm{O}_{2}$ is the most stable species ${ }^{14}$ ) in the inflammatory environment found in cancer and inflammatory diseases has been extensively exploited recently as stimulus for prodrug activation in site-selective drug delivery systems. ${ }^{15}$

In this regard, our group has previously reported promising preliminary results for the treatment of RA using boronic acid and thiazolidinone based MTX or AMT ROS-sensitive prodrugs in a collageninduced arthritis (CIA) mouse model of RA. ${ }^{16,17}$ Among the set of compounds previously synthesized and investigated (Figure 1), prodrugs 1, 2, and $\mathbf{3}$ showed good physicochemical and pharmacokinetic properties in vitro, as well as equivalent efficacy and lower toxicity in comparison to parental drugs in vivo.
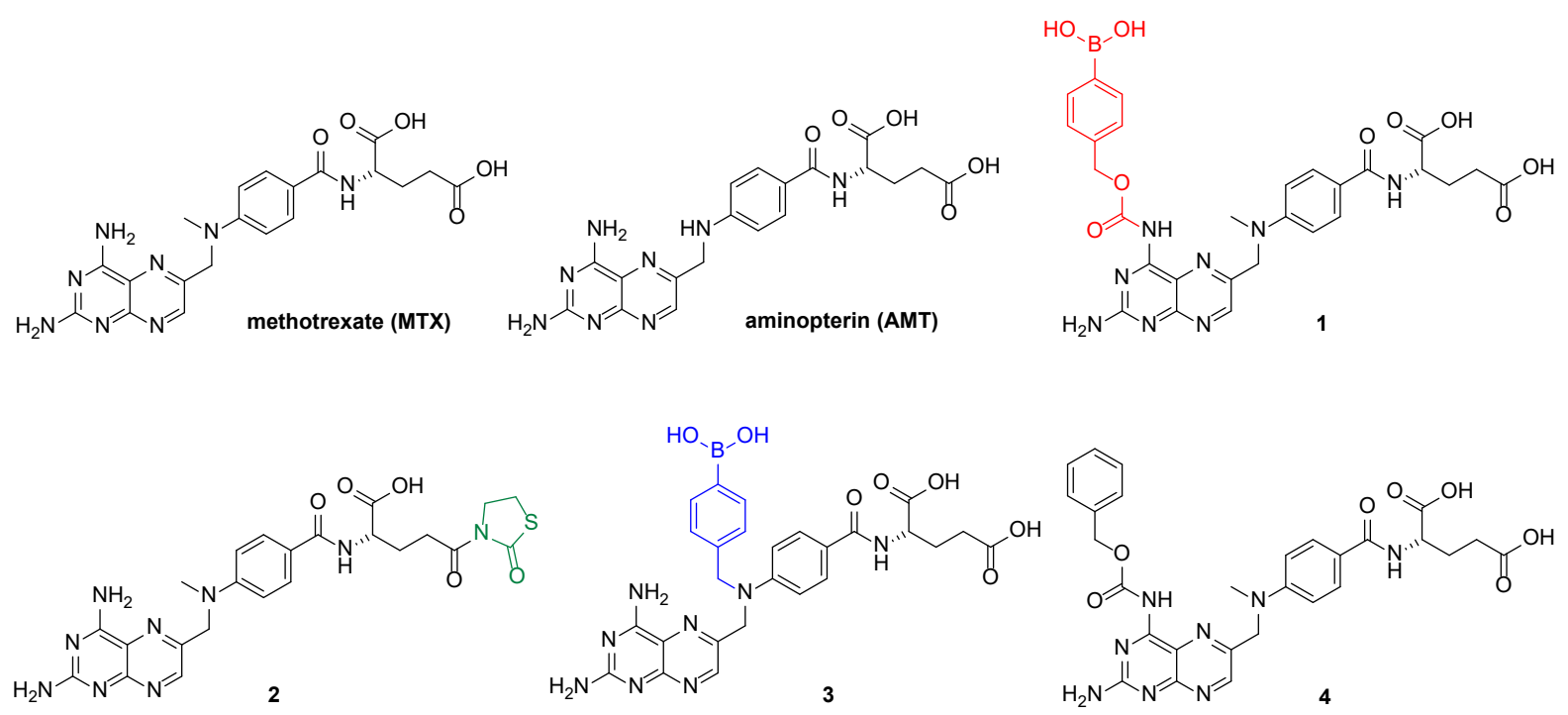

Figure 1: Structures of compounds investigated in the current study. ${ }^{16,17}$ 
Following these results, we herein present additional in vivo studies and further in vitro biological evaluation to assess the prodrugs activation by ROS and their biological profile compared to the parent drugs. In this regard, we also present the synthesis and biological evaluation of the negative control of prodrug $\mathbf{1}$, compound $\mathbf{4}$, lacking the ROS sensitive boronic acid moiety.

\section{Results and discussion}

In vivo efficacy validation in rat CIA model of $R A$ and preliminary toxicity

The aim of this study was to investigate the efficacy of the prodrugs $\mathbf{1}, \mathbf{2}, \mathbf{3}$, and their parent drugs MTX and AMT in a rat CIA animal model. This model was chosen because it mimics, to a large extent, the criteria used for diagnosis of rheumatoid arthritis in humans. ${ }^{18}$

A dosing regimen equimolar to $0.3 \mathrm{mg} / \mathrm{kg}$ MTX with daily intraperitoneal (i.p.) injections was chosen and to minimize the anti-inflammatory effects of $\mathrm{DMSO},{ }^{19}$ its concentration was kept to $2 \%(\mathrm{v} / \mathrm{v})$. Therapeutic intervention was initiated at the onset of the disease (when a mean arthritis severity score $>2$ was reached, on day 17) and terminated at day 31 (Supporting Information). Disease progression was followed macroscopically throughout the experiment and the results reported in Figure 2 (A, B). As evident from the figure, animals treated with prodrug 1 showed significantly ameliorating effects on disease until termination of the treatment, similarly to MTX treatment. Comparatively, animals treated with prodrug $\mathbf{2}$ had significantly higher arthritis severity.

As a first estimate of drug tolerability, the body weight of the rats was evaluated as an indicator of general health (Figure 2, B). Animals treated with prodrugs 1, 2, and $\mathbf{3}$ had a significantly higher weight compared with MTX treated animals. Animals treated with prodrug $\mathbf{3}$ had significantly higher arthritis severity compared with the AMT group, but also a higher average body weight. No adverse effects from treatments were observed in animals treated with the prodrugs $\mathbf{1}, \mathbf{2}$, and $\mathbf{3}$. AMT-administered animals displayed a severe decline in general health and were removed from the study pretermination on day 20-21. Animals treated with MTX also lost weight from day 23 , declined in general health and were removed pre-termination from days 24-29.

A)

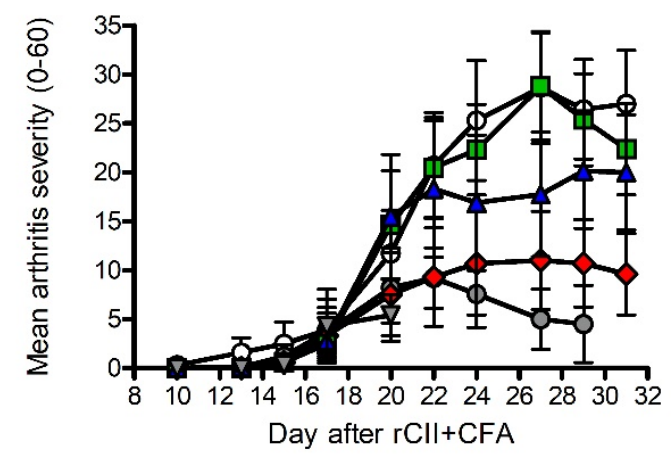

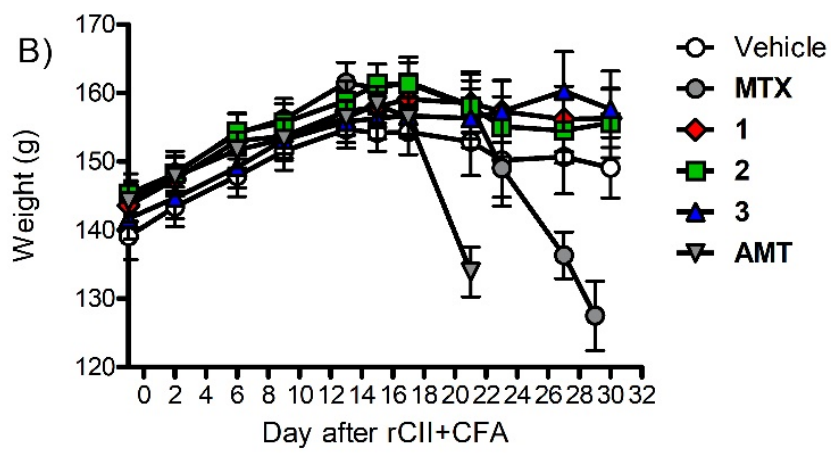

Figure 2: A) suppression of CIA development in rats after treatment with $\mathbf{M T X}(0.30 \mathrm{mg} / \mathrm{kg}$, i.p.), prodrug $\mathbf{1}(0.42$ $\mathrm{mg} / \mathrm{kg}$, i.p.), prodrug 2 (0.36 mg/kg, i.p.), prodrug $3(0.38 \mathrm{mg} / \mathrm{kg}$, i.p.), AMT $(0.29 \mathrm{mg} / \mathrm{kg}$, i.p.), and vehicle $(\mathrm{n}=8$ per group, $n=10$ for vehicle). Dark agouti (DA) rats were given the indicated amounts of compound daily, starting at onset of disease (day 17), and disease progression was evaluated three times per week. A macroscopic scoring system of the four limbs ranging from 0 to 15 (1 point per swollen toe, 1 point per swollen foot knuckle, and 5 
points for swollen ankle) was used for a maximal score of 60 per rat. Data represents mean values of arthritic score \pm SEM. B) the general health of mice was evaluated as the average body weight during collagen-induced arthritis as an indication of drug tolerability. Measurements were performed three times per week. Five animals, one in the vehicle group, two in prodrug $\mathbf{2}$ group and two in prodrug $\mathbf{3}$ group were sacrificed pre-termination, due to a high score. Animals in the MTX group were removed on days 24, 27-29 and the animals in the AMT group were removed on day 22 due to a decline in general health. Data represents mean values of body weight \pm SEM. Please note that statistical analysis and comparison between compounds of interest and parental drug can be found in Supporting Information (Figure S1 and Figure S2).

Micronuclei are extra-nuclear bodies that contain chromosomes fragments and/or whole chromosomes that come from DNA breakage or disruption of the mitotic apparatus and their presence is a good indication of genotoxicity of the compounds under study. ${ }^{20} \mathrm{~A}$ micronucleus assay was performed according to the protocol reported in the Supporting information. The experiment demonstrates a significantly lower micronuclei count in animals treated with prodrug 1 in comparison to all other treatments including MTX (Figure 3).

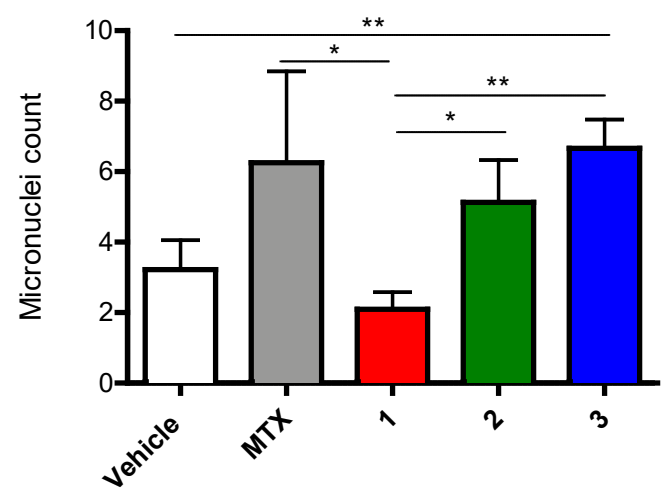

Figure 3: Evaluation of genotoxicity by bone marrow cell extraction and staining was performed according to the procedure reported in the Supporting Information. Observations were made with a Leica microscope (EpiFluorescence- DMRE) with a 100x oil immersion objective and micronuclei were manually counted from five images from a central area of the smear acquired from each animal using LARS.4.8 software. Graph represents the mean of total micronuclei count per animal for each treatment group. * represents a p-value $<0.05, * *$ represents a $\mathrm{p}$-value $<0.01$. Micronuclei example pictures can be found in Supporting Information (Figure S3).

\section{Cytotoxicity - cell viability and induction of apoptosis}

In order to better understand the results observed for the in vivo study and the data previously reported, ${ }^{16,17}$ we further investigated the biological profile and in vitro activity of prodrugs $\mathbf{1}, \mathbf{2}$, and $\mathbf{3}$. The negative control of prodrug $\mathbf{1}$, compound $\mathbf{4}$ (Figure 1) lacking the boronic acid moiety, was synthesized (synthesis and characterization in the Supporting Information, Figure S4) to demonstrate the role of the boronic acid moiety in ROS activation and release of MTX. ${ }^{21,22}$

It is important to show that the prodrugs are not cytotoxic in cells when not activated by ROS. To assess this issue, the cytotoxicity of the compounds of interest at different ROS concentrations was assessed. HL-60 (human leukemia cancer cell line), HEK293 (human embryonic kidney cell line), and 
HeLa (cervical cancer cell line) were chosen for their different capacity of ROS production and scavenging. ${ }^{23-25}$ Moreover, pyruvate was used as an active ROS scavenger ${ }^{26,27}$ and ROS levels were investigated by using fluorescence from the ROS probe $2^{\prime}, 7^{\prime}$-dichlorodihydrofluorescein diacetate ( $\mathrm{H}_{2}$ DCF-DA, Supporting Information). As supported by Figure S5, HEK293 cell line has a similar ROS production regardless of whether pyruvate is added to the media. ${ }^{24}$ The scavenging capacity of pyruvate is much more evident in the HL-60 cell line, where an 8.7-fold decrease in the ROS level was observed after 48 hours in the presence of pyruvate. Cell viability after $48 \mathrm{~h}$ of cells treated with prodrug 1, 2, 3, their parental drugs MTX/AMT, and compound 4, was evaluated for HL-60, HEK293 and HeLa cell lines, also using pyruvate as ROS scavenger (Table 1).

Table 1: IC 50 (mean of at least three replicates \pm SEM, nM) values of compounds 1-4, MTX, and AMT in HL-60, HEK293, and HeLa.

\begin{tabular}{ccccccc}
\hline Compd. & \multicolumn{7}{c}{ IC 50 (mean \pm SEM, nM) } \\
\cline { 2 - 7 } & \multicolumn{2}{c}{ HL-60 } & \multicolumn{2}{c}{ HEK293 } & \multicolumn{2}{c}{ HeLa } \\
\cline { 2 - 7 } $\mathbf{1}$ & $(+)$ pyr & $(-)$ pyr & $(+)$ pyr & $(-)$ pyr & $(+)$ pyr & $(-)$ pyr \\
$\mathbf{n y y y y y y}$ & $203.2 \pm 38.8$ & $40.3 \pm 5.6$ & $191.8 \pm 9.5$ & $62.9 \pm 7.6$ & $193.5 \pm 17.3$ & $156.0 \pm 25.0$ \\
$\mathbf{3}$ & $36.0 \pm 3.9$ & $40.0 \pm 7.0$ & nd & nd & $207.2 \pm 127.6$ & $163.7 \pm 15.1$ \\
$\mathbf{4}$ & $38.3 \pm 6.9$ & $7.5 \pm 0.8$ & nd & nd & $42.2 \pm 5.0$ & $19.2 \pm 3.3$ \\
MTX & nd & $>1000$ & nd & $>1000$ & nd & nd \\
AMT & $9.8 \pm 1.3$ & $8.9 \pm 1.5$ & $35.0 \pm 0.1$ & $28.6 \pm 4.3$ & $59.3 \pm 0.1$ & $21.0 \pm 0.1$ \\
\hline
\end{tabular}

nd = not determined

From the results reported in Table 1, there is a clear difference in cytotoxicity between prodrugs 1-4 and their parent drugs MTX and AMT. Interestingly, cytotoxicity of the prodrugs toward all the cell lines was significantly lower with added pyruvate, presumably because the ROS scavenger inhibited the release of the parent drug. For prodrugs 2 and $\mathbf{3}$, the $I_{50}$ fold difference to MTX and AMT respectively is not large, but for prodrug 1 , the difference to $\mathbf{M T X}$ is up to 20 fold in $\mathrm{HL}-60$ (+) pyruvate (Figure 4). As expected, pyruvate does not seem to play any role in the mechanism of toxicity for MTX and AMT, while, especially for prodrug 1, the difference between (+) and (-) pyruvate is 5 fold in HL60 and HEK293 cell lines (Figure 4). To have a more detailed and realistic comparison, compound 4 was tested in HL-60 and HEK293 cell lines (-) pyruvate. It afforded a much higher IC $C_{50}$ value ( $>1 \mu \mathrm{M}$ ) compared to MTX and AMT, confirming the importance of the boronic acid moiety and its selfimmolative, oxidative deboronation as the mechanism of prodrug activation.

A)

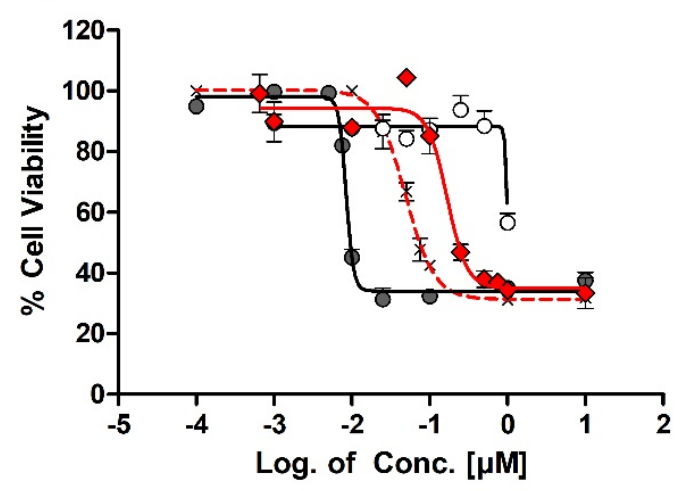

B)

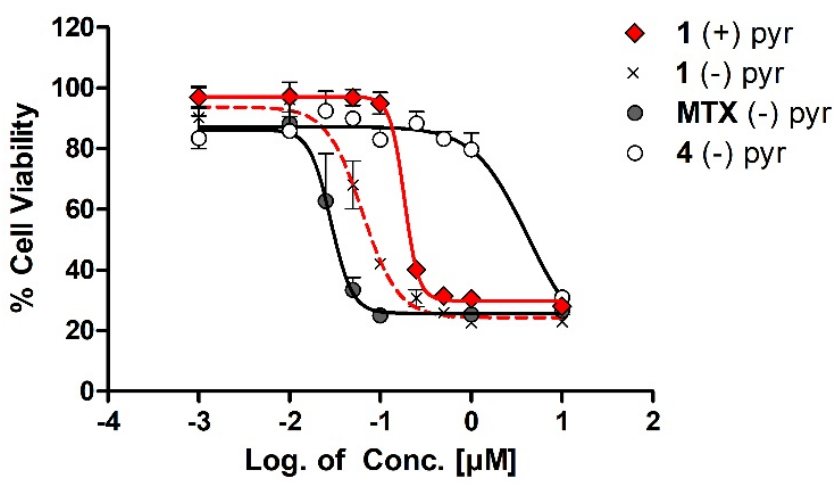


Figure 4: Cell viability of prodrug 1 ( \pm pyruvate), MTX (- pyruvate), and negative control 4 (- pyruvate) in HL-60 (A) and HEK293 (B) cell lines. Results were calculated as mean of at least three replicates (mean $\pm S E M, n=3$ ).

The mechanism by which MTX exhibits its anti-inflammatory effect in RA have been connected to the induction of apoptosis. ${ }^{28}$ The induction of apoptosis by MTX and prodrug 1 were investigated by flow cytometry in HL-60 cells (-) pyruvate treated with $10 \mu \mathrm{M}, 1 \mu \mathrm{M}$, and $0.1 \mu \mathrm{M}$ of compound, similar to previous experiments conducted for MTX. ${ }^{29}$ As shown in Figure 5, the percentage of apoptotic cells gradually increased from around $3 \%$ of the vehicle (DMSO $0.1 \%$ ) to around $17 \%$ as the HL-60 cells were treated with increasing concentration of prodrug 1 and MTX. The difference in apoptotic cells percentage between cells treated with prodrug 1 and $\mathbf{M T X}$ was highest at $0.1 \mu \mathrm{M}$, where MTX resulted in $14 \%$ apoptotic cells and treatment with 1 afforded only $7 \%$. The flow cytometry results confirm the viability measurements reported in Table 1 obtained using the Alamar blue assay.
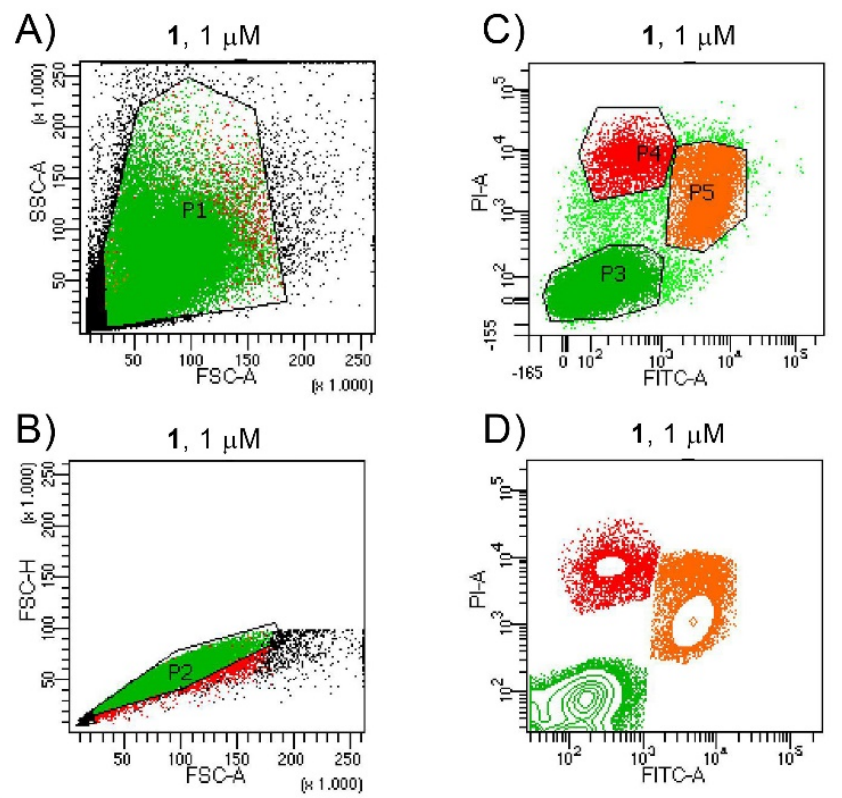

E)

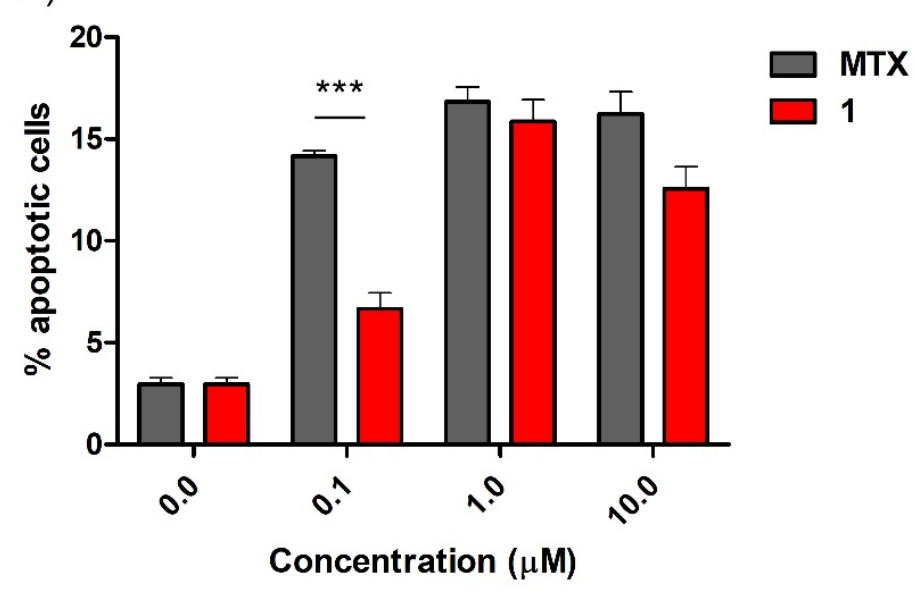

Figure 5: Flow cytometric analysis of AnV and PI stained HL-60 cells in RPMI media, treated with prodrug 1 (1 $\mu \mathrm{M}$ ) for 48 hours (for MTX treated cells and other concentrations, see Supporting Information Figure S6): (a) shows all the data obtained when samples were analyzed at 100000 events per second; (b) P2 indicates cell singlets; (c) indicates different cell populations: P3 is viable cells, while P4 and P5 are dead cells; (d) contour plot 
of the cell populations; (e) percentage of apoptotic cells (P4 + P5) as a function of the concentration of 1 and MTX. Results were calculated as mean of at least triplicates (mean $\pm S D, n \geq 3$ ). Statistics were calculated using a two-tailed unpaired t-test, where $\mathrm{p}<0.05$ was considered significant. $* * *$ represent a $\mathrm{p}$-value $<0.001$.

To account for the relatively high activity of prodrugs 1-3 (IC 50 values of 7-200 nM) as well as the ability of 1 to induce apoptosis, the presence of residual ROS in the media and the chemical stability of the molecules during the assay conditions were investigated.

\section{In vitro evaluation}

Among all the different prodrugs synthesized, 1 was considered the most promising both in terms of efficacy in the rat CIA model, but also when comparing the relative toxicity of the prodrug and its parent drug. In order to further explain the in vivo and cellular results, we investigated the stability and ADME profile of $\mathbf{1}$ compared to MTX and the control compound $\mathbf{4}$ (Table 2). The experiments were designed to investigate the ROS activation of $\mathbf{1}$ and to understand if the activity stems from unspecific hydrolysis or can be attributed to selective activation by ROS.

Table 2: Pharmacokinetic and physiochemical properties of 1, 4, and MTX. Values are an average of at least three measurements \pm standard deviation (SD).

\begin{tabular}{|c|c|c|c|c|c|c|c|c|c|c|}
\hline & $\begin{array}{c}\mathrm{H}_{2} \mathrm{O}_{2} \\
\text { activation } \\
(1 / 0.25 \\
\mathrm{mM}) \\
\mathrm{t}_{1 / 2}(\mathrm{~h})\end{array}$ & $\begin{array}{c}\text { PBS } \\
\text { stab. } \\
\mathrm{t}_{1 / 2} \\
\text { (h) }\end{array}$ & $\begin{array}{l}\text { Culture } \\
\text { media } \\
\text { stab. }^{a} \\
\mathrm{t}_{1 / 2}(\mathrm{~h})\end{array}$ & $\begin{array}{l}\text { Culture } \\
\text { media } \\
\text { stab. in } \\
\text { the } \\
\text { presence } \\
\text { of } \\
\text { HEK293 }^{\text {b }} \\
\mathrm{t}_{1 / 2}(\mathrm{~h})\end{array}$ & $\begin{array}{c}\text { Culture } \\
\text { media } \\
\text { stab. after } \\
\text { pre- } \\
\text { incubation } \\
\text { with } \\
\text { HEK293c }^{c}\end{array}$ & $\begin{array}{l}\text { Culture } \\
\text { media } \\
\text { stab. in } \\
\text { the } \\
\text { presence } \\
\text { of HEK293 } \\
\text { and PQ } \\
(10 \mathrm{mM})^{\mathrm{b}} \\
\mathrm{t}_{1 / 2}(\mathrm{~h}) \\
\end{array}$ & $\begin{array}{c}\text { Rat } \\
\text { Plasma } \\
\text { stab. } \\
\mathrm{t}_{1 / 2}(\mathrm{~h})\end{array}$ & $\begin{array}{l}\text { Rat } \\
\text { microsomes } \\
\text { stab., CL'int } \\
(\mathrm{mL} / \mathrm{min} / \mathrm{kg})\end{array}$ & $\begin{array}{c}\text { PAMPA } \\
\left(10^{-6}\right. \\
\mathrm{cm} / \mathrm{s})\end{array}$ & $c \operatorname{cog} P^{d}$ \\
\hline 1 & $0.29 / 2.34^{16}$ & $>24^{16}$ & $3.4 \pm 0.6$ & $\begin{array}{l}107.2 \pm \\
41.3\end{array}$ & $16.1 \pm 8.9$ & $\begin{array}{c}63.2 \pm \\
11.6\end{array}$ & $16.4 \pm 4.1$ & $1.8 \pm 0.8$ & $<1.50$ & -0.59 \\
\hline 4 & $>24$ & nd & $>24$ & nd & nd & nd & nd & nd & $<1.50$ & 1.10 \\
\hline MTX & nd & $>24$ & $>24$ & $>24$ & nd & nd & nd & $1.5 \pm 0.7$ & $<1.50$ & -0.42 \\
\hline
\end{tabular}

a media used is without pyruvate and the measurements are in the absence of cells

${ }^{b}$ media used is without pyruvate and the media is sampled and analyzed at different time points

${ }^{c}$ media used is without pyruvate and pre-incubated with HEK293 cells for $24 \mathrm{~h}$ before removal of cells and addition of compound

${ }^{d}$ consensus log $\mathrm{P}_{\mathrm{o} / \mathrm{w}}$ calculated with SwissADME ${ }^{30}$

Our group has previously reported the in vitro activation profile of prodrug 1 with $\mathrm{H}_{2} \mathrm{O}_{2} .{ }^{16}$ Compound 4 was subjected to similar conditions (Table 2, Figure S7), demonstrating that compound 4 was not converted to MTX over $24 \mathrm{~h}$. This experiment supports the specific activation of prodrug $\mathbf{1}$ by ROS in vitro and its stability to unspecific background hydrolysis.

MTX was stable for $24 \mathrm{~h}$ in PBS and culture media both in the presence and absence of HEK293 cells (Table 2, Figure S8). Similarly, prodrug 1 was stable in PBS, but its half-life in culture media was reduced to $3.4 \mathrm{~h}$, with only $1 \%$ of 1 remaining after 24 h (Table 2, Figure S9). In contrast, 4 was stable in culture media for $24 \mathrm{~h}$. A likely explanation for this observation is the presence of ROS in the media. ${ }^{31,32}$ 
Interestingly, 1 displayed better chemical stability in culture media after pre-incubation with cells and in media where HEK 293 cells are present - up to $80 \%$ of the prodrug remained in the media after $24 \mathrm{~h}$ (Table 2, Figure S9). As previously reported, ${ }^{33}$ this can likely be explained by antioxidants released by the cells that help maintaining ROS homeostasis, resulting in reduced activation of prodrug $\mathbf{1}$ to MTX. ${ }^{34}$

To further link activation of 1 with ROS, media stability during HEK293 cell growth with added paraquat (PQ) was tested (Table 2, Figure S9). $P Q$ is a bipyridyl quaternary ammonium salt known to induce cellular ROS production, ${ }^{35}$ which was confirmed using the DCF assay, in which the relative ROS levels in HEK293 cells with and without $10 \mathrm{mM} \mathrm{PQ}$ were measured (Table 2, Figure S10). The stability of prodrug 1 in culture media in the presence of HEK293 with PQ $(10 \mathrm{mM})$ in the first $24 \mathrm{~h}$ was similar to the one of 1 without PQ and a small difference could be observed only after 48 h (Figure S9), in accordance with previous reports of $\mathrm{PQ}$ induction of ROS levels for prochelators. ${ }^{36}$

Plasma stability was examined in reconstituted freeze dried rat plasma diluted 1:1 with PBS to ensure a pH of $7.4 .{ }^{37}$ At $37{ }^{\circ} \mathrm{C}$, the half-life of 1 was determined as $16 \pm 4 \mathrm{~h}$ indicating good plasma stability (Table 2, Figure S11).

Metabolic stability was evaluated by determining the apparent intrinsic clearances ( $C L^{\prime}$ int) in pooled rat liver microsomes. The apparent intrinsic clearance was calculated to be $1.8 \pm 0.8 \mathrm{~mL} / \mathrm{min} / \mathrm{kg}$ for prodrug 1 and $1.5 \pm 0.7 \mathrm{~mL} / \mathrm{min} / \mathrm{kg}$ for $\mathbf{M T X}$ indicating low intrinsic clearance and a profile similar to MTX $^{38}$ (Table 2, Figure S12).

The parallel artificial membrane permeability assay (PAMPA) assay gives a quick, simple determination of passive transport through biological membranes. ${ }^{39} \mathrm{~A}$ new artificial membrane that consists of a lipid/oil/lipid tri-layer in the porous filter was used, as it is known to give good predictability and agreement with data obtained for absorption in the Caco- 2 cell line..$^{40}$ The results of the permeability are reported as a permeability coefficient ( $\mathrm{Pe}$, for high permeability, $\mathrm{Pe}>1.50 \times 10^{-6} \mathrm{~cm} / \mathrm{s}$ ) and compared to caffeine, known as a well-permeable molecule. ${ }^{40,41}$ As shown in Table 2, MTX, prodrug $\mathbf{1}$, and negative control compound $\mathbf{4}$ displayed no permeability. ${ }^{42}$ The hydrophilicity of prodrug $\mathbf{1}$ is similar to MTX (clogP, Table 2) explaining the low permeability. MTX is actively transported across membranes by different transporters ${ }^{7,43}$ and, having ruled out passive diffusion, prodrug 1 is likely activated to MTX by extracellular ROS and then internalized in cells as MTX.

\section{Conclusions}

In summary, we have described further in vivo and in vitro studies to support the use of different prodrugs, and in particular 1, as a ROS sensitive strategy for targeted MTX therapy in RA.

These findings confirmed that $\mathbf{1}$ is activated by ROS and is efficacious in a rat CIA model of arthritis, exhibiting lower toxicity than MTX. Although the activity of prodrug 1 in our in vivo model resembled MTX, it did not surpass it, and further studies will be needed to distinguish between a targeted therapy and a systemic slow-release of MTX. In this regard, ROS sensitive functionalities, as the boronic acid, are labile functionalities, sensitive to ROS but in some extent also to background hydrolysis. Our cellular studies demonstrate that the activity of prodrug $\mathbf{1}$ is clearly attenuated compared to the parent drug while the in vivo efficacy is maintained with significantly reduced toxicity. Nonetheless, it is virtually impossible to avoid some non-specific activation in vivo and it must be expected that the 
prodrug can be activated in tissues other than synovium, also by mechanisms that are independent of ROS levels. The consequence of this is that the biodistribuition of the targeted therapy can be unpredictable, also because boronic acids can react with endogenous nucleophiles, leading to unfavorable pharmacokinetics. ${ }^{44-47}$

For these reasons, evidence for accumulation, activation and retention of prodrugs at the site of inflammation is needed to support the theory of targeted therapy. The synovial fluid concentrations of a small molecule or a delivery system is determined by synovial blood flow, plasma concentration, microvascular permeability, and lymphatic drainage. Unfortunately, the primary obstacle preventing use of rodent synovial fluid for accumulation studies is the lack of reliable methods for its harvesting. ${ }^{48,49}$ Some methods have been developed recently, ${ }^{48,49}$ but have been mainly used to quantify inflammatory mediators and cells. ${ }^{50}$ Moreover, quantification of MTX, other DMARDs and derivatives has mostly been done in human synovial fluid ${ }^{51}$ or in larger model animals such as rabbits. $^{52,53}$

Further investigations that address the points discussed above are important for the successful advancement of prodrug strategies relying on ROS activation and should be taken into account as early as possible in discovery.

\section{Acknowledgments}

We are grateful for financial support from the Independent Research Fund Denmark (grant no. 701700026) and the Technical University of Denmark (PoC funding). We would like to thank Asger Hegelund Olsen for his help with the in vitro evaluation and Christian Oettinger for his contribution to the synthesis of compound 4.

\section{References}

(1) Smolen, J. S.; Aletaha, D.; McInnes, I. B. Rheumatoid Arthritis. Lancet 2016, 388 (10055), 2023-2038.

(2) Mclnnes, I. B.; Schett, G. The Pathogenesis of Rheumatoid Arthritis. N. Engl. J. Med. 2011, 365 (23), 2205-2219.

(3) Veale, D. J. Cellular and Molecular Perspectives in Rheumatoid Arthritis. 2017, 343-354.

(4) Gubner, R.; August, S.; Ginsberg, V. Therapeutic Suppression of Tissue Reactivity. 2. Effect of Aminopterin in Rheumatoid Arthritis and Psoriasis. Am. J. Med. Sci. 1951, 221, 176-182.

(5) Goldin, A.; Venditti, J. M.; Humphreys, S. R.; Dennis, D.; Mantel, N.; Greenhouse, S. W. A Quantitative Comparison of the Antileukemic Effectiveness of Two Folic Acid Antagonists in Mice. JNCI J. Natl. Cancer Inst. 1955, 15 (6), 1657-1664.

(6) Brown, P. M.; Pratt, A. G.; Isaacs, J. D. Mechanism of Action of Methotrexate in Rheumatoid Arthritis, and the Search for Biomarkers. Nat. Rev. Rheumatol. 2016, 12 (12), 731-742.

(7) Cutolo, M.; Sulli, A.; Pizzorni, C.; Seriolo, B.; STRAUB, R. H. Anti-Inflammatory Mechanisms of Methotrexate in Rheumatoid Arthritis. Ann. Rheum. Dis. 2001, 60 (8), 729-735.

(8) Chan, E. S. L.; Cronstein, B. N. Methotrexatehow Does It Really Work? Nat. Rev. Rheumatol. 
2010, $6(3), 175-178$.

(9) Wang, W.; Zhou, H.; Liu, L. Side Effects of Methotrexate Therapy for Rheumatoid Arthritis: A Systematic Review. Eur. J. Med. Chem. 2018, 158, 502-516.

(10) Wruck, C. J.; Fragoulis, A.; Gurzynski, A.; Brandenburg, L.-O.; Kan, Y. W.; Chan, K.; Hassenpflug, J.; Freitag-Wolf, S.; Varoga, D.; Lippross, S.; et al. Role of Oxidative Stress in Rheumatoid Arthritis: Insights from the Nrf2-Knockout Mice. Ann. Rheum. Dis. 2011, 70 (5), $844 \mathrm{LP}-850$.

(11) Wei, X.; Wu, J.; Zhao, G.; Galdamez, J.; Lele, S. M.; Wang, X.; Liu, Y.; Soni, D. M.; Purdue, P. E.; Mikuls, T. R.; et al. Development of a Janus Kinase Inhibitor Prodrug for the Treatment of Rheumatoid Arthritis. Mol. Pharm. 2018, 15 (8), 3456-3467.

(12) Feng, N.; Yang, M.; Feng, X.; Wang, Y.; Chang, F.; Ding, J. Reduction-Responsive Polypeptide Nanogel for Intracellular Drug Delivery in Relieving Collagen-Induced Arthritis. ACS Biomater. Sci. Eng. 2018, 4 (12), 4154-4162.

(13) Rautio, J.; Meanwell, N. A.; Di, L.; Hageman, M. J. The Expanding Role of Prodrugs and Development. Nat. Rev. Drug Discov. 2018, 17 (8), 559-587

(14) Groeger, G.; Quiney, C.; Cotter, T. G. Hydrogen Peroxide as a Cell-Survival Signaling Molecule. Antioxid. Redox Signal. 2009, 11 (11), 2655-2671.

(15) Peiró Cadahía, J.; Previtali, V.; Troelsen, N. S.; Clausen, M. H. Prodrug Strategies for Targeted Therapy Triggered by Reactive Oxygen Species. Med. Chem Commun. 2019, 10 (9), 1531-1549

(16) Peiró Cadahía, J.; Bondebjerg, J.; Hansen, C. A.; Previtali, V.; Hansen, A. E.; Andresen, T. L.; Clausen, M. H. Synthesis and Evaluation of Hydrogen Peroxide Sensitive Prodrugs of Methotrexate and Aminopterin for the Treatment of Rheumatoid Arthritis. J. Med. Chem. 2018, 61 (8), 3503-3515.

(17) Andersen, N. S.; Peiró Cadahía, J.; Previtali, V.; Bondebjerg, J.; Hansen, C. A.; Hansen, A. E.; Andresen, T. L.; Clausen, M. H. Methotrexate Prodrugs Sensitive to Reactive Oxygen Species for the Improved Treatment of Rheumatoid Arthritis. Eur. J. Med. Chem. 2018, 156, 738-746.

(18) Hou, W.; Meng, L.; Tian, L.; Zhu, W.; Jiang, C.; Lu, S. A Systematic Comparison between Collagen-Induced Arthritis and Pristane-Induced Arthritis in Dark Agouti Rats. Clin. Exp. Rheumatol. 2010, 28 (4), 532-538.

(19) Colucci, M.; Maione, F.; Bonito, M. C.; Piscopo, A.; Di Giannuario, A.; Pieretti, S. New Insights of Dimethyl Sulphoxide Effects (DMSO) on Experimental in Vivo Models of Nociception and Inflammation. Pharmacol. Res. 2008, 57 (6), 419-425.

(20) Luzhna, L.; Kathiria, P.; Kovalchuk, O. Micronuclei in Genotoxicity Assessment: From Genetics to Epigenetics and Beyond. Front. Genet. 2013, 4, 131.

(21) Zheng, S.; Guo, S.; Zhong, Q.; Zhang, C.; Liu, J.; Yang, L.; Zhang, Q.; Wang, G. Biocompatible Boron-Containing Prodrugs of Belinostat for the Potential Treatment of Solid Tumors. ACS Med. Chem. Lett. 2018, 9 (2), 149-154.

(22) Bhagat, S. D.; Singh, U.; Mishra, R. K.; Srivastava, A. An Endogenous Reactive Oxygen Species (ROS)-Activated Histone Deacetylase Inhibitor Prodrug for Cancer Chemotherapy. ChemMedChem 2018, 13 (19), 2073-2079.

(23) Pan, Z.; Zhang, J.; Ji, K.; Chittavong, V.; Ji, X.; Wang, B. Organic CO Prodrugs Activated by Endogenous ROS. Org. Lett. 2018, 20 (1), 8-11. 
(24) Skarbek, C.; Serra, S.; Maslah, H.; Rascol, E.; Labruère, R. Arylboronate Prodrugs of Doxorubicin as Promising Chemotherapy for Pancreatic Cancer. Bioorg. Chem. 2019, 91, 103158.

(25) Doskey, C. M.; Buranasudja, V.; Wagner, B. A.; Wilkes, J. G.; Du, J.; Cullen, J. J.; Buettner, G. R. Tumor Cells Have Decreased Ability to Metabolize H2O2: Implications for Pharmacological Ascorbate in Cancer Therapy. Redox Biol. 2016, 10, 274-284.

(26) Kelts, J. L.; Cali, J. J.; Duellman, S. J.; Shultz, J. Altered Cytotoxicity of ROS-Inducing Compounds by Sodium Pyruvate in Cell Culture Medium Depends on the Location of ROS Generation. Springerplus 2015, 4, 269.

(27) Long, L. H.; Halliwell, B. Artefacts in Cell Culture: Pyruvate as a Scavenger of Hydrogen Peroxide Generated by Ascorbate or Epigallocatechin Gallate in Cell Culture Media. Biochem. Biophys. Res. Commun. 2009, 388 (4), 700-704.

(28) Wessels, J. A. M.; Huizinga, T. W. J.; Guchelaar, H.-J. Recent Insights in the Pharmacological Actions of Methotrexate in the Treatment of Rheumatoid Arthritis. Rheumatology 2007, 47 (3), 249-255.

(29) Herman, S.; Zurgil, N.; Deutsch, M. Low Dose Methotrexate Induces Apoptosis with Reactive Oxygen Species Involvement in T Lymphocytic Cell Lines to a Greater Extent than in Monocytic Lines. Inflamm. Res. 2005, 54 (7), 273-280.

(30) Daina, A.; Michielin, O.; Zoete, V. SwissADME: A Free Web Tool to Evaluate Pharmacokinetics, Drug-Likeness and Medicinal Chemistry Friendliness of Small Molecules. Sci. Rep. 2017, 7, 42717.

(31) Grzelak, A.; Rychlik, B.; Bartosz, G. Light-Dependent Generation of Reactive Oxygen Species in Cell Culture Media. Free Radic. Biol. Med. 2001, 30 (12), 1418-1425.

(32) Schnellbaecher, A.; Binder, D.; Bellmaine, S.; Zimmer, A. Vitamins in Cell Culture Media: Stability and Stabilization Strategies. Biotechnol. Bioeng. 2019, 116 (6), 1537-1555.

(33) Hašková, P.; Jansová, H.; Bureš, J.; Macháček, M.; Jirkovská, A.; Franz, K. J.; Kovaříková, P.; Šimůnek, T. Cardioprotective Effects of Iron Chelator HAPI and ROS-Activated Boronate Prochelator BHAPI against Catecholamine-Induced Oxidative Cellular Injury. Toxicology 2016, $371,17-28$.

(34) Birben, E.; Sahiner, U. M.; Sackesen, C.; Erzurum, S.; Kalayci, O. Oxidative Stress and Antioxidant Defense. World Allergy Organ. J. 2012, 5 (1), 9-19.

(35) Bus, J. S.; Gibson, J. E. Paraquat: Model for Oxidant-Initiated Toxicity. Environ. Health Perspect. 1984, 55, 37-46.

(36) Kielar, F.; Helsel, M. E.; Wang, Q.; Franz, K. J. Prochelator BHAPI Protects Cells against Paraquat-Induced Damage by ROS-Triggered Iron Chelation. Metallomics 2012, 4 (9), 899909.

(37) Kerns, E. H.; Di, L. Plasma Stability, in: Drug-like Properties: Concepts, Structure Design and Methods, first ed., Elsevier Inc., London, 2008; pp 169-177.

(38) Obach, R. S. Prediction of Human Clearance of Twenty-Nine Drugs from Hepatic Microsomal Intrinsic Clearance Data: An Examination of In Vitro Half-Life Approach and Nonspecific Binding to Microsomes. Drug Metab. Dispos. 1999, 27 (11), 1350-1359.

(39) Kansy, M.; Senner, F.; Gubernator, K. Physicochemical High Throughput Screening: Parallel Artificial Membrane Permeation Assay in the Description of Passive Absorption Processes. J. 
Med. Chem. 1998, 41 (7), 1007-1010.

(40) Chen, X.; Murawski, A.; Patel, K.; Crespi, C. L.; Balimane, P. V. A Novel Design of Artificial Membrane for Improving the PAMPA Model. Pharm. Res. 2008, 25 (7), 1511-1520.

(41) Latacz, G.; Lubelska, A.; Jastrzębska-Więsek, M.; Partyka, A.; Sobiło, A.; Olejarz, A.; KucwajBrysz, K.; Satała, G.; Bojarski, A. J.; Wesołowska, A.; et al. In the Search for a Lead Structure among Series of Potent and Selective Hydantoin 5-HT 7 R Agents: The Drug-Likeness in Vitro Study. Chem. Biol. Drug Des. 2017, 90 (6), 1295-1306.

(42) He, J.; Abraham, M. H.; Acree, W. E.; Zhao, Y. H. A Linear Free Energy Analysis of PAMPA Models for Biological Systems. Int. J. Pharm. 2015, 496 (2), 717-722.

(43) Yokooji, T.; Mori, N.; Murakami, T. Site-Specific Contribution of Proton-Coupled Folate Transporter/Haem Carrier Protein 1 in the Intestinal Absorption of Methotrexate in Rats. J. Pharm. Pharmacol. 2009, 61 (7), 911-918.

(44) António, J. P. M.; Russo, R.; Carvalho, C. P.; Cal, P. M. S. D.; Gois, P. M. P. Boronic Acids as Building Blocks for the Construction of Therapeutically Useful Bioconjugates. Chem. Soc. Rev. 2019, 48 (13), 3513-3536.

(45) António, J. P. M.; Gonçalves, L. M.; Guedes, R. C.; Moreira, R.; Gois, P. M. P. Diazaborines as New Inhibitors of Human Neutrophil Elastase. ACS Omega 2018, 3 (7), 7418-7423.

(46) Springsteen, G.; Wang, B. A Detailed Examination of Boronic Acid-Diol Complexation. Tetrahedron 2002, 58 (26), 5291-5300.

(47) Yang, W.; Gao, X.; Wang, B. Boronic Acid Compounds as Potential Pharmaceutical Agents. Med. Res. Rev. 2003, 23 (3), 346-368.

(48) Barton, N. J.; Stevens, D. A.; Hughes, J. P.; Rossi, A. G.; Chessell, I. P.; Reeve, A. J.; McQueen, D. S. Demonstration of a Novel Technique to Quantitatively Assess Inflammatory Mediators and Cells in Rat Knee Joints. J. Inflamm. 2007, 4, 1-8.

(49) Seifer, D. R.; Furman, B. D.; Guilak, F.; Olson, S. A.; Brooks, S. C.; Kraus, V. B. Novel Synovial Fluid Recovery Method Allows for Quantification of a Marker of Arthritis in Mice. Osteoarthr. Cartil. 2008, 16 (12), 1532-1538.

(50) Tan, C.; Zhang, J.; Chen, W.; Feng, F.; Yu, C.; Lu, X.; Lin, R.; Li, Z.; Huang, Y.; Zheng, L.; et al. Inflammatory Cytokines via Up-Regulation of Aquaporins Deteriorated the Pathogenesis of Early Osteoarthritis. PLoS One 2019, 14 (8), e0220846.

(51) Tishler, M.; Caspi, D.; Graff, E.; Segal, R.; Peretz, H.; Yaron, M. Synovial and Serum Levels of Methotrexate during Methotrexate Therapy of Rheumatoid Arthritis. Rheumatology 1989, 28 (5), 422-423.

(52) Bonanomi, M. H.; Velvart, M.; Weder, H. G. Fate of Different Kinds of Liposomes Containing Dexamethasone Palmitate after Intra-Articular Injection into Rabbit Joints. J. Microencapsul. 1987, 4 (3), 189-200.

(53) Tamura, T.; Higuchi, Y.; Kitamura, H.; Murao, N.; Saitoh, R.; Morikawa, T.; Sato, H. Novel Hyaluronic Acid-Methotrexate Conjugate Suppresses Joint Inflammation in the Rat Knee: Efficacy and Safety Evaluation in Two Rat Arthritis Models. Arthritis Res. Ther. 2016, 18 (1), 111. 